\title{
GUERRA COLONIAL E INDEPENDÊNCIA DE ANGOLA: O FIM DA GUERRA NÃO É O FIM DA GUERRA
}

\section{Resumo:}

O objetivo deste trabalho é efetuar uma breve análise do processo de independência de Angola, levado a efeito pelos seus grandes movimentos de libertação nacional nos marcos do colapso do colonialismo português. Tentaremos analisar brevemente $o$ momento de passagem de uma guerra de natureza essencialmente anticolonial para o cenário das disputas internas (guerra civil) configurado no período em que a independência estava "agendada", embora ainda não configurada - que correspondeu ao momento de "suspensão" caracterizado pelo governo de transição entre janeiro e novembro de 1975 .

Palavras-chave: Angola; Guerra Anticolonial; Independência.

\begin{abstract}
:
The objective of this work is to make a brief analysis of Angola's independence process, carried out by its great national liberation movements in the framework of the collapse of Portuguese colonialism. We will briefly try to analyze the time of transition from a primarily anticolonial nature of war for the scenario of internal disputes (civil war) set in the period when independence was "scheduled", although not yet set - which corresponded to the time of "suspension" characterized by the transitional government between January and November in 1975 .
\end{abstract}

Keywords: Angola; Anticolonial War; Independence. 


\section{INTRODUÇÃo}

A historiografia sobre Angola ainda é pouco difundida em nossos cursos universitários que, com raras e boas exceções, trata da história da África a partir de uma epistemologia eurocêntrica. Como sugere Ferro, é

imprescindível levar em conta o passado dessas sociedades [colonizadas], pois dele dependeu amplamente a relação entre colonizadores e colonizados. Hoje não mais se considera, como se fazia antigamente, que esses povos não tiveram história; já não se fala em "séculos obscuros", e sim em "séculos opacos", já que incompreensíveis para os que entravam em contato com aqueles povos. (FERRO. 1996, p. 12)

Mesmo o termo "descolonização" nos remete a uma lógica europeizante, visto que sugere implicitamente que os europeus, impedidos ou cansados de sua tarefa de colonizadores, propõem-se agora a descolonizar - o que não poderia ser mais errôneo em se tratando da história do povo angolano, cuja longa trajetória de guerra contra o jugo português aconteceu às suas próprias expensas. É o caso de nos perguntarmos, como o fez Ferro,

devemos o fim da colonização à luta de libertação dos povos subjugados e vencidos, e só a ela, ou temos de imputá-la também à decadência das metrópoles, incapazes de administrar o imenso capital que haviam acumulado? Ou terá sido o resultado das pressões do mundo exterior conjugado a outros fatores? (FERRO, 1996, p. 300)

Por trás da questão estão os movimentos de libertação da África, que ao final da Segunda Guerra Mundial eclipsaram o imperialismo europeu para iniciar uma nova etapa na história dos nacionalismos africanos.

Para entendermos certos traços da história recente angolana, é preciso situar o processo de independência de Angola nos quadros da crise do colonialismo europeu, que ganha força no período do imediato pós-Segunda Guerra Mundial.

O fator decisivo para a essa crise foram os confrontos da Segunda Guerra Mundial, uma vez que os territórios metropolitanos se tornaram palco imediato de conflitos altamente destrutivos que, além de imbricarem em amplos esforços humanos e materiais que tendiam a diminuir sua capacidade em gerir o aparato administrativo e colonial de que dispunham, também foram notórios por proverem "a prova de que os brancos e seus Estados podiam ser derrotados, total e vergonhosamente" (HOBSBAWM, 1995, p. 212). Ademais, a exemplo do caso francês, 
em que suas colônias foram importantes partícipes nos teatros de operação e que de forma análoga à metrópole (separada em República de Vichy e França Livre, de De Gaulle) foram separadas em duas partes (África-Ocidental e África-Equatorial), surgiu a estranha e incômoda situação em que o colonizador e o colonizado lutaram lado a lado em prol da liberdade do primeiro (CROWDER, in: UNESCO, 2010.). Ainda que o período imediatamente posterior à Segunda Guerra fosse de tentativas de restabelecer os laços coloniais de forma a fomentar a reconstrução europeia, os movimentos de libertação nacional que se iniciaram na década de 1930 tenderam a amadurecer ao longo da Segunda Guerra, ao passo que a ascensão dos Estados Unidos como centro hegemônico do mundo capitalista tendia a solapar o tipo de relação de quase autarquia que os impérios coloniais europeus mantinham com suas colônias em busca do favorecimento da livre circulação das empresas transnacionais.

A marcha rumo às independências se tornou irrefreável em inícios da década de 1950 e este princípio foi consagrado na Carta da Organização das Nações Unidas (ONU) no seu capítulo XI, intitulado "Declaração Sobre os Territórios NãoAutônomos”, onde se lê em seu Artigo $73^{\circ}$ a positivação do primado dos interesses dos habitantes locais à gradativa promoção do seu autogoverno:

Promover o seu governo próprio, ter na devida conta as aspirações políticas dos povos e auxiliá-los no desenvolvimento progressivo das suas instituições políticas livres, de acordo com as circunstâncias peculiares a cada território e seus habitantes, e os diferentes graus do seu adiantamento [...] (ONU. Cartas das Nações Unidas, 1945.)

As descolonizações não poderiam mais sair da pauta política das metrópoles coloniais e, a exemplo da Conferência de Brazzaville de 1944, organizada por De Gaulle$^{1}$, discussões e planejamentos acerca das descolonizações começaram a ser tratados com o cuidado de que os interesses econômicos nas colônias não fossem abalados totalmente. A fórmula para as descolonizações após a Segunda Guerra era a de ceder autonomia administrativa ao governo local, de forma a fazer a profilaxia para eventuais e prováveis revoluções sociais por parte da população negra, e manter, na questão econômica, os laços das arcaicas instituições coloniais sob a forma de

\footnotetext{
1 A Conferência de Brazzaville (1944, ex-Congo francês) reuniu os administradores coloniais que haviam colaborado com os Aliados, de forma a empreender, junto com De Gaulle, evoluções em relação à administração colonial e, assim, aumentar, ainda que minimamente, sua margem de governabilidade. Cf. História geral da África. Brasília: UNESCO, 2010.
} 
acordos, tratados e outros órgãos que acabavam por beneficiar a elite dirigente europeizada e a economia primário-exportadora.

Estavam dados os ingredientes para o colonialismo que prescindia da administração direta da metrópole, uma vez que a inserção das colônias no mercado internacional lhes propiciara ser dependentes econômica e tecnologicamente, além de privadas de estruturas industriais integradas e dirigidas por um status quo profundamente identificado com a ex-metrópole, o que dificultou, em muito, a criação de um governo autocentrado empenhado em reformas sociais que abarcassem a grande massa da população. Esse cenário de "descolonização" gradativa começou a chamar-se "neocolonialismo", ao qual socorreram muito bem a Inglaterra, com sua Commonwealth, e a França, com a União Francesa e sua romântica ideia de "comunidade francófona".

Mas, para entender a história recente de angola, é necessário também situar o seu processo de independência nos quadros de um combate anticolonial contra o inimigo comum português, em um cenário de guerra intraestatal que assumiria os contornos dos grupos envolvidos nos conflitos da guerra fria. Essa passagem ocorre de forma gradual, embora possamos dizer que o Acordo de Alvor tenha subitamente chamado a atenção internacional para a situação angolana (ainda que tenha sido o ponto nevrálgico dessa clivagem), conquanto a composição ideológica e de ordem sociopolítica dos grupos nacionalistas angolanos, desde o momento de sua criação, tenha se proposto a aproximações de elementos externos.

Assim, o Movimento Popular pela Libertação de Angola (MPLA), em função de seu referencial marxista-leninista, e da idealização de um programa revolucionário para a Angola independente, aproximou-se do campo soviético e cubano, ainda que seus dirigentes tenham reiteradamente informado à opinião pública sua disposição de não-alinhamento²; a Frente Nacional de Libertação de Angola (FNLA), por sua vez, carecia de um planejamento explícito para o que viria após o expurgo do colonialismo português, ao passo que a bandeira do anticomunismo, que o uniria aos

\footnotetext{
${ }^{2}$ Sobre a composição do MPLA e sua filiação ideológica, Aniceto Afonso e Carlos de Matos Gomes afirmam que "o MPLA é um partido de quadros, de mestiços e dos antigos assimilados, tendo implantação nas cidades, mesmo que apenas por adesão sentimental” (AFONSO, e GOMES, 2000, p. 70) Na mesma obra, um pouco antes, dizem que "o MPLA foi, desde o primeiro momento, uma organização nacional, e ainda que a sua principal base de apoio tenha sido a etnia mbundo, que se estendia de Luanda a Malange, contou sempre com apoios noutros grupos tribais. Aglutinou, além disso, elementos da pequena burguesia negra e mestiça e dos setores operários. Contrariamente à FNLA, tinha uma ideologia mais definida e, com o tempo, evidenciou-se a sua raiz marxista". (idem, op. cit, p. 64). E mais adiante, afirmam que "os mestiços... desempenharam papel de grande importância e representaram o essencial dos quadros marxistas do MPLA". (idem, ibidem, p. 69)
} 
Estados Unidos e, posteriormente, à África do Sul, funcionaria como uma ferramenta bastante eficaz para combater o MPLA. A União Nacional para Independência Total de Angola (UNITA) não teria uma atuação tão premente nessa fase da vida angolana quanto os outros dois grupos, em que podemos dizer que a coalizão com a África do Sul, em meados de 1975, tenha obliterado sua atuação como grupo individual, tornando-se a própria imagem do rompante sul-africano.

\section{DA GUERRA DE LIBERTAÇÃo NACIONAL À QUEDA DO ESTADO NOVO (1961-1974)}

Em Angola, dois movimentos foram os principais responsáveis por atrair a adesão popular e a atenção internacional para a luta de independência angolana: o Movimento Popular de Libertação Nacional (MPLA) e a União das Populações do Norte de Angola (UPNA), depois transformada simplesmente em União das Populações de Angola (UPA). 3 Diferentes em seus programas políticos e nas suas bases regionais de apoio, estes dois grupos não foram os únicos a formar coro político ao longo das décadas de 1950 e 1960, embora tenham se tornado, pelos motivos que veremos a seguir, os únicos que sobreviveram ao crivo da Política Internacional e de Defesa do Estado (PIDE), a principal ferramenta de repressão política, tanto em solo europeu quanto africano, do governo de António Salazar e de seu sucessor, Marcello Caetano.

O fim da Segunda Guerra trouxe o refluxo da capacidade administrativa dos antigos impérios coloniais europeus, o que veio ao encontro do recrudescimento dos nacionalismos africanos propiciando um grande salto em seus processos de independência. Angola não passaria incólume a este movimento que havia levado a crítica ao colonialismo à ordem do dia, pois além do valor simbólico impingido na liberação dos países vizinhos, cuja apoteose foi o ano de 1960, o Ano Africano,4 o

\footnotetext{
${ }^{3}$ Um terceiro grupo, a UNITA, surgiu na segunda metade da década de 1960. Contudo, sua organização e chefia (Jonas Savimbi) eram provenientes dos outros dois grupos; além disso, a importância efetiva da UNITA nas páginas da história angolana não esteve tanto na fase da guerra anticolonial, mas justamente após a independência - quando os Estados Unidos, sob a égide da Doutrina Reagan, juntamente com a África do Sul, o apoiaram aberta e diretamente como forma de combater o governo do MPLA, apoiado diretamente por Cuba. Tudo isso compete para que MPLA e UPA sejam os grupos nacionalistas principais na fase que se pretende analisar.

${ }^{4}$ Em 1960, a maior parte das colônias belgas, francesas e inglesas na África tornou-se independente: "Camarões, Congo-Brazzaville (atual República Popular do Congo), Gabão, Tchad, República Centro-Africana, Togo, Costa do Marfim, Daomé (atual Benin), Alto Volta (Atual Burkina-Faso), Niger, Nigéria, Senegal, Mali, Madagascar (atual República Malgaxe), Somália, Mauritânia e Congo-Leopoldville (Depois Zaire e atual República Democrática do Congo). Entre 1961 e 1966, foi a vez de Serra Leoa, Tanzânia, Uganda, Ruanda, Burundi, Quênia, Gâmbia, Botswana e Lesoto" (VISENTINI, 2010, p. 30).
} 
intenso diálogo entre os pensadores e políticos africanos dos países recém-libertos, ou em situação de guerra anticolonial, proveu o contexto africano de larga circulação de subsídios político-ideológicos com os quais arguir contra o colonizador - tanto em plano simbólico, como concretamente.

Assim, dois dos grandes arautos do pensamento anticolonial africano, ainda que imbuídos de projetos independentistas bastante diferentes, participaram pessoalmente da fase de gestação da luta anticolonial angolana na virada da década de 1950 à de 1960: Kwane Nkrumah e Frantz Fanon. O primeiro, Presidente de Gana, auxiliou na fuga de estudantes provenientes de Angola e Moçambique que estavam estudando em Portugal quando a guerra em Angola foi deflagrada no início de 1961 e sabia-se que a reação da PIDE não tardaria (BITTENCOURT, 1997, p. 27); o segundo, quando da ocasião da II Conferência dos Povos Africanos de 1960, em Túnis (Tunísia), encontrou-se com os expoentes políticos tanto do MPLA quanto do UPA5 e, a partir de sua experiência da guerra de libertação nacional argelina, foi um importante incentivador da nacionalização da luta armada em Angola e da interiorização desta luta (BITTENCOURT, 1997, p. 9). Além disso, ainda que suas participações físicas tenham sido pontuais no caso angolano, são imensuráveis as implicações de suas ideias para o desenvolvimento dos processos independentistas da África, cujos movimentos do Pan-Africanismo e da Negritude, caros a um e a outro, constituíram ferramentas riquíssimas de crítica às "descolonizações gradualistas" e ao modelo neocolonial subjacente a elas. ${ }^{6}$

\footnotetext{
${ }^{5}$ Estavam lá Viriato da Cruz e Lúcio Lara, ambos do MPLA, assim como Holden Roberto, líder da UPA. Em conjunto, assinaram uma Declaração de Compromisso, em que foi grifada a necessidade de "estabelecer o mais cedo possível um programa concreto de ação para 1960 e que conduza nossos povos à independência no mais breve espaço de tempo" (Declaração de Compromisso, Arquivo Pessoal de Lúcio Lara, apud BITTENCOURT, Op. cit. anexo I).

${ }^{6}$ Kwane Nkrumah (1909-1972) foi um entusiasta do Pan-Africanismo. Movimento originalmente criado nas antigas colônias inglesas caribenhas e norte-americanas para a promoção dos direitos da população negra em um ambiente notavelmente racista, o Pan-Africanismo teve vários desdobramentos nas independências africanas no após Segunda Guerra. Nkrumah, que fora Primeiro Ministro e depois Presidente de Gana (1957-1960; 19601966) advogava a união política das ex-colônias africanas como forma de evitar a "balcanização" da África que beneficiaria unicamente à Europa. Suas ideias fomentaram a criação do chamado Grupo de Casablanca em 1961, em contraposição ao Grupo de Brazzaville (que seguia uma linha substancialmente mais conservadora e de natureza neocolonial), que, conjuntamente, dariam lugar à Organização da Unidade Africana (OUA) em 1963. A respeito de Nkrumah e seu modelo de Pan-Africanismo, ver Mazrui (In: UNESCO, 2010, V. VIII). Frantz Fanon (1925-1961), psiquiatra e membro ativo da Frente Nacional de Libertação da Argélia, como vários outros pensadores do pós-colonialismo, recebeu grandes influências do movimento Négritude (Negritude), surgido entre os descendentes de escravos das Antilhas francesas, cujo grande símbolo fora o líder da revolução haitiana, Toussaint L'Ouverture. Este movimento objetivava, nos campos político e cultural, a restauração da identidade negra, solapada pelos séculos de escravidão e de colonização da África; a Negritude nunca constituiu um bloco monolítico de atuação, conquanto tenha logrado inspirar movimentos muito diversos ao longo do século XX: do Harlem Renaissance, de recuperação de uma estética negra nas artes e literatura, surgido em Nova Iorque (EUA)
} 
Não cabe aqui, no espaço deste artigo, fazer um inventário completo, ano a ano, das sortes e revezes de cada movimento de libertação durante os treze anos (19611974) em que se dispuseram a lutar contra a "nação pluricontinental" portuguesa; tal tarefa tampouco seria possível, devido à dificuldade extrínseca do mapeamento de uma guerra tipicamente de guerrilha, que se arrastara por um longo período sobre um território vastíssimo. Muito brevemente analisaremos apenas os momentos que julgamos cruciais para a vida dos movimentos nacionalistas, sempre que possível ligando-os às relações que estes grupos logravam fazer com países estrangeiros essencialmente veladas 7 - por acreditarmos que o caráter dessas relações foi determinante na passagem da guerra anticolonial para a guerra que foi iniciada, nos quadros da Guerra Fria, quando Portugal deixasse de ser uma variável a ser considerada nas relações políticas de Angola no cenário internacional.

Podemos distinguir três grandes fases nos anos que vão de 1961 à queda do Estado Novo português em $1974^{8}$. Esta diferenciação, necessariamente sintética, só pode ser feita em relação aos sucessos e insucessos no campo das operações militares, deixando de fora a atuação da população civil que, embora tenha sido fator determinante para o sucesso do projeto nacional angolano, não caberia no espaço deste trabalho. A primeira fase correspondeu ao período 1961-1966, quando a ação de guerrilha foi iniciada no interior do território (que até então estivera restrita ao litoral e região centro-oeste) sob atuação do MPLA; a segunda fase, de 1965-1970, firmou o êxito deste grupo na cobertura do território, tornando-se o único movimento de alcance realmente "nacional" de Angola à época; o terceiro momento, 1970-1974, marcou o recuo da ação do MPLA, por conta da perda substancial de contingentes localizados em bases ao leste, por conta de desentendimentos internos, que depois se uniram ao grupo de Holden Roberto (UPA/FNLA) ou ao grupo de Jonas Savimbi (UNITA).

\footnotetext{
na década de 1930, às entusiásticas críticas formuladas em solo africano quanto ao enraizamento do status quo europeu em suas ex-colônias, por exemplo. A maior crítica à Negritude está em sua "demasiada ênfase" à necessidade de um "racismo anti-racista", que por vezes desaguou em violência ativa, de suas propostas políticas. O próprio Fanon seria criticado por "realçar a necessidade da violência" para combater as permanências psicológicas e materiais da situação pós-colonial; contudo, descartá-lo como um mero correligionário da ação destemperada e irrefletida é incorrer em simplificações perigosas, que não levam em conta as especificidades da história e da sociedade africanas (WALLESTEIN, 1970, pp. 222-231).

${ }^{7}$ Visto que por mais que a ajuda externa chegasse ao território angolano, dificilmente seria através dos portos de Luanda, pois o caráter dessas relações, até 1974, foi bastante dúbio, uma vez que país algum se posicionou abertamente contra Portugal e ao lado de Angola nos campos de batalha.

${ }^{8}$ Estas fases não correspondem a distintos processos históricos cujas análises estejam consolidadas, mas os eventos que, pela importância que tiveram para os grupos nacionalistas, os seus sucessos e malogros frente a Portugal nos ajudam a dar melhor inteligibilidade e coesão à narrativa.
} 
Após a estrondosa ofensiva portuguesa aos acontecimentos do começo de 1961, os dirigentes tanto do MPLA quanto do UPA viram-se obrigados a buscar fontes alternativas para ações futuras. Assim, Holden Roberto dirigiu-se ao Congo Leopoldville, onde formou em 1963, com apoio logístico e material deste país, o Governo Revolucionário de Angola no Exílio (GRAE), que seria reconhecido pela Organização da Unidade Africana (OUA) como o único movimento de libertação em Angola tão logo essa instituição fosse consolidada ao início de 1963. Objetivando a modernização do discurso do grupo, o UPA passou a ser chamado, desde então, de Frente Nacional de Libertação de Angola. O MPLA, por outro lado, saiu muito mais fragmentado do rompante português de 1961, de forma que teve sua atuação reduzida a florestas no norte de Luanda (Davidson, 1970, pp. 37-49.); seus dirigentes também se dirigiram ao Congo ex-belga, onde se encontrariam com Agostinho Neto, que retornara de Portugal. 9

Sediados no Congo Leopoldville, a atuação do MPLA estaria amplamente limitada, pois o ambiente era naturalmente muito mais favorável ao grupo de Holden, quem, pessoalmente, mandava obstruir o transporte e a passagem de membros do grupo de Agostinho pela fronteira. Apesar disso, a margem de manobra do MPLA sofreu uma reviravolta em 1963, quando Alphonse Massamba-Delbát instituiu um governo revolucionário de inspiração marxista-leninista no Congo Brazzaville, abrindo ao MPLA a possibilidade de mudar para um ambiente muito mais acolhedor na outra margem do Rio Congo.

Com o advento da utilização de território do Congo Brazzaville, tornara-se essencial ao MPLA ter o domínio de Cabinda, pois este pequeno território de enclave era uma ponte privilegiada de passagem entre Brazzaville e Angola, e foi nesta primeira ação de guerrilha, da qual se saíram vitoriosos, que a guerra realmente começava para o MPLA (Davidson, 1970, pp. 37-49). Nesta conjuntura, e a partir de bases alocadas em território congolês, URSS e Cuba começaram a enviar aporte

\footnotetext{
${ }^{9}$ Antonio Agostinho Neto (Bengo, 1922 - Moscou, 1979) era filho de uma professora primária e de um pai pastor metodista; com bolsa de estudos patrocinada pela Igreja Americana Metodista, pôde ir a Lisboa estudar Medicina. Em sua trajetória universitária, foi preso em 1953 por pertencer a um grupo com ligações com o Partido Comunista Português (PCP); em 1955 voltou a ser preso, dessa vez por ser filiado ao PCP. Foi solto em 1957. Retornou a Angola ao final de 1959 e instalou seu consultório no Bairro Operário de Luanda. (PEIXOTO, 2009).
} 
material e homens para o treinamento de forças militares para auxílio do MPLA e de Alphonse. ${ }^{10}$

A segunda fase da ação empreendida pelos grupos nacionalistas denotou a ascensão do MPLA em sua tarefa de compor uma unidade de atuação sobre o território angolano. Mais uma vez, foi através da solidariedade dos vizinhos africanos que o grupo de Agostinho logrou êxitos no campo de batalha: em 1965, o MPLA conseguiu o consentimento dos governos de Zâmbia e Tanzânia para fazer linhas de acesso através de seus territórios, o que lhe proporcionou melhor movimentação logística no interior de Angola e, além disso, abriu rotas seguras para o acesso às armas da URSS através do Oceano Índico, visto que a posição de tropas portugueses ao longo do Atlântico tornou a utilização dos portos de Angola infactível. Beneficiando-se dessa nova situação, o MPLA começou a operar, em março de 1966, no distrito de Moxico; no Lunda, a partir de maio de 1968 e, a seguir, chegou a Bié em junho de 1969, de onde partiram ao distrito de Malanje ainda no mesmo ano (Davidson, 1970, pp. 37-49). Tal era a propagação da presença do MPLA no interior de Angola ao final de década de 1970, que o historiador Basil Davidson, que analisou os percursos políticos da África Austral desde o começo da década de 1950, foi levado a dizer que

Parece-me inquestionável que o MPLA é hoje o único movimento nacional em Angola - o único movimento, isto é, que ganhou o apoio da maioria dos grupos étnicos na maior parte do país - e, além disso, que o MPLA é o único movimento com qualquer força combatente eficaz [no interior]. (DAVIDSON, 1970, pp. 39-40)

Por força dessa nova realidade, ainda no ano de 1965 a OUA reconheceu o MPLA, ao passo que, em 1971, deixou de reconhecer o GRAE de Holden Roberto. O motivo para a mudança de posição da organização foi a descoberta de que a FNLA recebia suporte dos Estados Unidos, através do Congo Leopoldville, desde o início da década de 1960 - ao que veio adicionar a visível predileção de Mobutu, presidente deste país, pelos próprios Estados Unidos e seus parceiros, como o aliado forte para lidar com a África Austral. ${ }^{11}$

\footnotetext{
${ }^{10}$ Acredita-se que foi neste momento que os primeiros contatos entre o grupo de Agostinho e os cubanos tenham sido feitos. Che Guevara partiu de Havana para ver a situação do Congo Brazzavile em 1965 e, logo em 1966, Agostinho Neto foi a Cuba encontrar Fidel Castro (MARQUEZ. 1976).

${ }^{11}$ Mobutu dera um golpe de Estado em 1965, destituindo o então chefe de Estado Moisés Tchombe, iniciando um longo período de centralização política e ditadura pessoal baseada em um partido único, ao qual todos os
} 
A OUA, contudo, não era a única observadora da guerra de libertação angolana, pois a África do Sul, desde a década de 1950, deixava pouco espaço para dúvidas quanto ao perfil de potência regional que almejava para si (DAVIDSON, 1974, pp. 920) ${ }^{12}$, influenciando política e economicamente os países em seu entorno. A minoria branca de Pretória influenciava virtualmente todo o cone sul da África e ocupava, contrariando resoluções da ONU, o território da Namíbia. No entanto, desde 1966 o domínio sul-africano sobre este território foi sistematicamente afrontado pela ação do grupo guerrilheiro SWAPO (Organização do Povo do Sudoeste Africano) (VISENTINI, 2010, p. 30).

À Pretória interessava a manutenção do aparato administrativo português em Angola e Moçambique, uma vez que seus próprios interesses econômicos amparados amplamente no tripé formado por capital estrangeiro, industrialização e trabalho forçado propugnado pelo regime segregacionista do apartheid - sofreram sérios abalos com a revisão do já anacrônico sistema segregacionista dos bastiões brancos (DAVIDSON, 1974, pp. 9-20). Se paradoxais em tese, o lusotropicalismo e o apartheid serviram-se mutuamente por um longo tempo; a questão é como a África do Sul deveria reagir frente ao escalonamento da guerra de libertação angolana que parecia enfraquecer cada vez mais uma metrópole economicamente fragilizada.

Às apreensões da África do Sul quanto à falibilidade da contenção portuguesa ao nacionalismo angolano, devemos somar as características político-ideológicas de cada um dos grupos nacionalistas e da projeção que elas teriam sobre o, por enquanto hipotético, governo que ficasse sob sua responsabilidade.

Os vários anos de colonialismo europeu sobre a África trabalharam para que toda a infraestrutura, tanto material como administrativa, fosse voltada ao setor produtivo, com especial ênfase ao setor primário-exportador. O aparato logístico de transporte e escoamento de produtos, bem como os bens de capital, estava todo sob o poder da metrópole ou, como no caso específico de Portugal que servira de "testa de ferro" ao capital transnacional no século XX, em mãos de proprietários não-locais. Sendo assim, o processo de independência das colônias europeias tendeu a ser feito

\footnotetext{
cidadãos congoleses eram obrigatoriamente filiados. "Desde o golpe até sua derrubada Mobutu foi apoiado e sustentado pelos países ocidentais" (VISENTINI; RIBEIRO; PEREIRA, 2007. p. 101).

${ }^{12}$ A título de exemplo, o Primeiro Ministro sul-africano disse em 1968: "We are of Africa, we understand Africa, and nothing is going to prevent us from becoming the leaders of Africa in every field" (Newschek, November, 1968 apud DAVIDSON, op. cit.) "Nós somos da África, nós entendemos a África, e nada vai nos impedir de nos tornar os líderes da África em todos os campos”. Tradução livre nossa.
} 
de forma "gradual”, em que as elites governantes dos novos países agiam a partir de estreitas ligações com a antiga metrópole, institucionalizando uma continuidade política de tipo neocolonial. Exemplos notáveis disso foram os exitosos Commonwealth inglesa e, no caso francês,

os acordos de Yaoundé (1963-1969), e depois as Convenções de Lomé (a partir de 1975), e finalmente o estabelecimento da rede de cooperação da ACP (África, Caribe e Pacífico), [que] permitiram à França institucionalizar os laços neocoloniais, ao tornar os países africanos cativos do mercado europeu integrado (VISENTINI, 2010, p. 37).

Em outros casos, contudo, as nações africanas optaram por se tornar indepentes e, ao mesmo tempo, ter o controle dos recursos produtivos do novo país através da vontade do novo Estado, acarretando, em última instância, modificações estruturais na sociedade que existira até então. Esta tentativa de atingir uma reestruturação das bases sociais no Estado recém-liberto difere da simples supressão imediata do colonizador, conquanto a segunda opção acarretaria, segundo Chaliand, modificações menores, tais como a

eliminação dos elementos mais ligados ao exterior, indenização dos grandes proprietários de terras, por outro lado frequentemente cooptados para o aparelho de Estado, ou encorajados a investir no setor industrial [e a] constituição de uma pequena burguesia rural que se torna uma das bases sociais desses regimes. (CHALIAND, 1977, p. 120)

Essas "mudanças menores", numa palavra, davam grandes oportunidades de perpetuação dos laços do tipo neocolonial, ao gosto francês e inglês, como vimos, mas dificilmente praticável com um Estado português empobrecido - em que, na realidade, o seu neocolonialismo foi derrogado a outros países. O grupo de Agostinho Neto justamente alarmava os governantes sul-africanos por defender um projeto revolucionário nacional e social - não era apenas a cor da pele dos seus dirigentes, portanto, que colocava em risco o domínio dos capitais sul-africanos em Angola como também o domínio territorial sobre uma Namíbia crescentemente relutante. Ademais, a FNLA de Holden Roberto, cujas raízes étnicas mostraram inúteis as tentativas de Holden de "nacionalizar" o movimento, uma vez que mesmo os mulatos e negros de outras etnias eram sistematicamente rechaçados do grupo, tiveram motivos muito maiores para causar alarde na minoria branca (20\% da população) 
sediada em Pretória - e, no entanto, foi a este grupo e, posteriormente, à UNITA, que cederam ajuda.

Ao longo da guerra colonial, o MPLA efetivou campanhas de conscientização da população angolana de forma a desracializar o movimento e criar uma autoimagem positiva de unidade nacional em contraposição ao sectarismo étnico de Savimbi e Holden Roberto. A mesma característica que os fazia causar preocupação na África do Sul aproximava-os de Cuba na segunda metade da década de 1960 (o que, em última instância, foi o ponto fulcral para a roupagem de conflito leste-oeste que a independência tomou em seu último ano).

A terceira e última fase das operações da guerra de independência em Angola (1970-1974), contudo, proporcionou um desfecho preocupante para o grupo de Agostinho Neto. O front Leste, aberto na metade da década, sofreu uma pesada baixa a partir de descontentamentos do grupo liderado por Daniel Chipenda que, entre outros motivos, achavam-se desprivilegiados em relação à fronteira Norte, que esteve mais bem equipada; contudo, a revolta também recendia a questões etnicorraciais mal equacionadas. (PEIXOTO, 2012)

O MPLA, embora sendo o grupo territorialmente mais presente em Angola, esteve em posição delicada na entrada da década de 1970: "achatado" na fronteira Norte pela coalizão da FNLA e Congo Zaire, e competindo em forças no interior com a UNITA ${ }^{13}$, o grupo insurgente de Chipenda, e as tropas sul-africanas, cujo Exército moderno e bem equipado pôde marchar com facilidade através da Namíbia para dentro de Angola.

Quando em setembro de 1968, António Salazar, por motivos de saúde, viu-se afastado de seu cargo, Marcelo Caetano foi convidado para ocupar a posição que pertencia a Salazar há 38 anos. A pretérita atuação de Caetano lhe dera cores de liberal ante a opinião pública ${ }^{14}$ e, consequentemente, certa esperança de que sua política colonial não seguiria as mesmas linhas de Salazar. No entanto, quaisquer

\footnotetext{
${ }^{13}$ A UNITA fora criada em 1965 por Jonas Savimbi, que tivera experiências tanto com o MPLA quanto com a FNLA; este grupo lograria certo apoio da China, com a qual compartilhava a ideia maoísta de ação do campo à cidade. Estabelecera-se na região do Moxico, na qual pôde estabelecer unidades que representavam relativa obstrução às atividades do MPLA - o que só puderam efetivar através de um acordo tácito com o governo português (PEIXOTO, op. cit). Até a Revolução dos Cravos, no entanto, a participação da UNITA foi marginal. ${ }^{14}$ Marcello Caetano, em meados da década de 1950, à época na chefia do Ministério das Colônias de Salazar, havia viajado a Angola e Moçambique para averiguar a questão da grande fuga populacional que ocorria nestes territórios, ao que concluiu que as péssimas condições de vida como reflexo do trabalho por contrato eram o principal agente motivador. Retornando a Portugal, ele disse: "Necesito que se me den negros, es una frase que con frecuencia oí de los colonos: ¡Como si los negros fueran una cosa para ser dada!” (BENDER, 1980, p. 195).
} 
esperanças provaram-se rapidamente ilusórias, visto que as mudanças administrativas que Caetano efetivamente pôs em prática no começo da década de 1970, de forma a ceder certa autonomia administrativa a Angola, mostraram sem resultados práticos ou demasiadamente tardios para que pudessem abrandar o ritmo da guerra que àquela altura grassava não apenas em Angola, como também em Moçambique, Guiné Bissau e Cabo Verde. (DAVIDSON, 1970, p. 37-49)

O processo que culminou na derrubada do governo português em abril de 1974 fora impulsionado pela guerra colonial que se arrastava há treze anos. No plano interno, os gastos destinados à manutenção do aparato militar nas colônias portuguesas somavam suntuosas fatias do orçamento nacional, chegando a reter 50\% das despesas públicas. (PEIXOTO, 2012) No âmbito internacional, as pressões que surgiram a partir da ONU quanto ao colonialismo português, feitas desde tão cedo quanto à própria entrada de Portugal nesta instituição em $1955^{15}$, foram acrescidas de um paulatino esfriamento de relações com antigas parcerias face à estridente negativa portuguesa em abrandar seu posicionamento em relação à guerra africana tanto que Salazar, como seu sucessor Caetano, via como o resultado de ingerências externas, fosse por parte do Zaire e o "expansionismo de Mobutu” ou da URSS e "seu comunismo contagioso". (PEIXOTO, 2012, p. 122) Seja como for, a posição portuguesa era de que a guerra que acontecia em Angola, como também em Moçambique, Guiné Bissau e Cabo Verde, era fruto de motivações exógenas e estranhas ao corpo pluricontinental e multirracial da nação portuguesa, ao que se somou o discurso de que Portugal estaria efetuando obras de integração, antes de colonização.

Com o subterfúgio da "integração" eram rebatidas as críticas que surgiram no seio do governo português, tanto do lado das Forças Armadas, instituição que estava exaurida depois de tantos anos de guerra e com ampla inabilidade em prover novos quadros para mantê-la, quanto da camada mais liberal dos políticos que defendiam outro tipo de integração: com a Comunidade Europeia a que Portugal tinha grandes dificuldades em aderir pelo motivo de não compartilhar com os outros países europeus das suas visões em relação ao tipo de relacionamento que se deveria ter com suas possessões, ou ex-possessões, na África.

\footnotetext{
${ }^{15}$ Entre 1955 e 1974, Portugal seria mencionado em mais de 80 documentos produzidos pela Assembleia Geral da ONU em função das suas reiteradas negativas em dialogar a respeito de sua administração colonial; no Conselho de Segurança, os documentos críticos ou condenatórios ao colonialismo português foram 27 (entre 1961 e 1974) (ONU, 1974-1995).
} 
O discurso do deputado Águedo de Oliveira, na Assembleia Nacional portuguesa em seis de abril de 1961, portanto logo a seguir aos episódios que conflagraram a luta armada em Angola, é bastante elucidativo da pauta de política externa portuguesa que mudou muito pouco nos anos subsequentes:

A primeira pergunta que um político que folheia as Cartas do Atlântico, das Nações Unidas e outros textos de direito internacional formula, é esta: Em Nova Iorque está-se, na realidade, a organizar mundialmente a paz? Não está. Lançar pretos contra brancos, mestiços e outros pretos não é organizar a paz. Estimular, espicaçar, acalorar a insurreição, conspirar contra a segurança interna dos Estados, incentivar as revoltas dos povos de cor, criar antagonismos onde eles não existem, não é organizar a paz, mas promover a guerra. Intervir nos assuntos que afirmam a competência normal dos Estados é contrário às Cartas, aos seus fins, ao seu espírito, e é espalhar um fermento de conflitos e guerras. Os Estados Unidos estão agora a regressar à política do "irmão proletário", de que tão funestas provas colheram em 1946. (ASSEMBLEIA NACIONAL, 1961, pp. 512533)

A crítica aos Estados Unidos estava ligada à inesperada mudança de direção que esse país fizera ao apoiar a condenação do Conselho de Segurança da ONU, juntamente com a União Soviética, à violenta contrarreação portuguesa aos episódios angolanos do início de $1961^{16}$. Todavia, esse mesmo julgamento português não se restringiria às grandes potências do mundo bipolar, como também ao Terceiro Mundo e aos não-alinhados; Oliveira prossegue seu discurso em que podemos ver claramente o entendimento do governo salazarista em relação aos seus esforços por "integração":

Não façam jogos de palavras nem estabeleçam mais confusão de conceitos. Quando em Bandung, em Acra e no Cairo se fala em descolonização pretende-se o banimento dos Europeus, a revisão e reprovação total da acção secular europeia. Pretende-se herdar sem partilha as plantações, casas, escritórios, armazéns, oficinas, fábricas, portos, estradas, obra dos capitais, inteligência e trabalho europeu, tudo que é património público e privado, sem indemnização nem compensação. Integração significa descolonizar e todavia não querem que assim seja. Vejamos. Integração significa também descolonizar porque assegura independência nacional, desenvolvimento e vida que

\footnotetext{
${ }^{16}$ De acordo com Anderson, "a decisão de inverter a tradicional política do Departamento de Estado quanto à solidariedade atlântica nas questões coloniais foi tomada tão tarde que os Estados Unidos não tiveram tempo para avisar os seus estados-clientes [...] sobre a mudança" e completa citando excerto de uma matéria do New York Times, "e é possível que só o tivessem sabido quando Adlai E. Stevenson [representante Norte-americano na $\mathrm{ONU}]$ tomou a palavra no final do debate" (ANDERSON, 1966. p. 102-103).
} 
se pode chamar própria [...] Integração significa elevação do nível moral e civilizador até ao nível europeu. Significa assistência financeira, técnica, desenvolvimento económico e social - todauma obra imensa de associação e de intimidade nas ideias e nos factos. Significa unidade moral e política. (ASSEMBLEIA NACIONAL, 1961, pp. 512-533)

A elevação em nível moral que queriam os portuguesas se mostrava infensa às críticas, de onde quer que elas viessem: Estados Unidos, que estava a apoiar o irmão proletário, os Não-Alinhados (Bandung) e, por fim, até o campo de uma histórica parceria do governo de Portugal, o Brasil. Sumarizando sua fala, ao fim da qual foi amplamente aplaudido pelo auditório lotado de políticos, incluindo o próprio Salazar, Oliveira elencou os pontos importantes para serem levados em consideração na futura atuação de Portugal quanto ao ultramar, entre eles:

Fazer compreender aos dirigentes brasileiros, alguns imbuídos de romanticismo jurídico e não conseguindo raciocinar senão em termos americanos acerca da Europa e da África, que está em frente do Brasil, é ponto dominante no Sul Atlântico, mercado futuro, apoio, na futura divisão do Mundo em grandes comunidades e espaços. (ASSEMBLEIA NACIONAL, 1961, pp. 512-533)

Esse afrontamento explica-se pelo fato de que o Brasil ao longo da década de 1960 começou a mudar gradativamente seu posicionamento em relação à solidariedade aos povos em processo de independência na África e, ainda que num plano retórico, principalmente a partir da Política Externa Independente (PEI) formulada nos governos de Jânio Quadros e João Goulart17, mudou gradativamente da simpatia retórica ao rechaço concreto ao colonialismo português na década de 1970.

Com efeito, a África que o governo salazarista-marcelista tentava tão veementemente “civilizar", já não era mais a mesma de 1930, quando Salazar ascendera ao seu posto, uma vez que gradativamente as nações africanas foram acrescidas em sua atuação internacional, "seja através do clientelismo estabelecido com as ex-metrópoles, da ONU, do Grupo dos 77, da OPEP (Organização dos Países Exportadores de Petróleo) e/ou do Movimento dos Não-Alinhados”. (VISENTINI, 2010, p. 35)

\footnotetext{
${ }^{17}$ Para observar a visão da PEI acerca das independências africanas, ver CERVO (2010).
} 
Chegou a hora de Portugal dar provas de que não poderia mais manter sua posição de controle das peças de Angola e Moçambique no quebra-cabeças dos regimes de minorias brancas da África Austral. Na estranha posição em que se colocara, Portugal "constrangia" com seu anacronismo colonial suas parcerias mais antigas, a exemplo do Brasil, e não podia mais prover a estabilidade pacificadora de que tanto precisavam os capitais transnacionais instalados em suas colônias, ao passo que a prolongada desestabilização política tampouco agradava às suas contrapartes da OTAN. Era como se a persistência na ideia de manutenção de antigos títulos imperiais encapsulados na grandiloquência da "nação pluricontinental e multirracial" carregasse, em si, sua própria antítese - o que foi perspicazmente observado em comunicado da FRELIMO (Frente de Libertação de Moçambique) de 1969:

Outra contradição entre a política colonial e a política externa de Portugal é que enquanto necessita do suporte da África do Sul para manter Moçambique e Angola (como colônias portuguesas), é também temerosa de que a África do Sul possa tomar esses regimes com a ajuda das minorias brancas que residem lá. (FRELIMO, 25 de setembro de 1969, apud DAVIDSON, 1974, p. 13)

Lançando farpas a todos os "três mundos" que Bandung inaugurara em 1955, Salazar, como seu sucessor Caetano, logrou lançar o país a um profundo isolacionismo, difícil de ser contornado - mesmo seu histórico pilar de sustentação, a Igreja Católica, havia se afastado da cúpula portuguesa, recebendo, em 1970, Amílcar Cabral e Agostinho Neto de braços abertos no Vaticano. (Davidson, 1974, p. 13) Em 1965, Salazar já se apercebera desta conjuntura, que tenderia a se agravar ao longo dos anos, em discurso que se tornou o epíteto do isolacionismo português na virada da década de 1960 a 1970:

"Orgulhosamente sós" [...] Salazar defendia [...] a manutenção do
esforço de guerra português nas colônias africanas, definido como
uma "batalha em que - os portugueses europeus e africanos -
combatemos sem espectáculo e sem alianças, orgulhosamente sós".
(SALAZAR, 1965, apud, RODRIGUES, 2004, p. 8)

Apesar de a conjuntura internacional ter corroborado em larga escala para retirar as bases de apoio do governo salazarista-marcelista, o estopim de sua derrocada saiu de dentro do Estado português, mais precisamente de um dos braços fortes que haviam mantido este regime fascista em funcionamento por tanto tempo: as Forças Armadas. Antes de 1961, o contingente militar em Angola não ultrapassava 
a casa dos 5.000, mas ao final deste ano o número ascendeu a 33.00o homens. Em 1965, o Exército Português somava o contingente de 57.000 homens e, em 1973, o número aumentava para 66.500.

É preciso lembrar que Angola não correspondia ao único front de batalha travada por Portugal, pois em 1963 a guerra de libertação estourou em Guiné Bissau, seguida por Moçambique em 1968. Além disso, em 1961 a União Indiana ocupou militarmente e incorporou o enclave português de Goa, sem encontrar resistência significativa, (Peixoto, 2012) o que corroborou para tornar visível a vulnerabilidade do aparato militar português em manter seu potentado ultramarino.

A proeminência dos gastos militares em um país que, em 1960, tinha o nível de vida mais baixo da Europa Ocidental, abaixo da Grécia ou do México (ANDERSON, 1966), tendeu a ser insustentável a longo prazo. No entanto, este fator não demoveu o envio de tropas e a manutenção da guerra e do aparato logístico e material, altamente dispendiosos, inerentes a ela. Isso tudo acontecia ao largo das crescentes insatisfações das Forças Armadas quanto à precariedade da assistência dada aos regressados da África, não raras vezes com sérias sequelas físicas e psicológicas, ou às famílias daqueles que não regressariam. ${ }^{18}$ Além disso, a necessidade constante de formação de novos quadros dirigentes desagradava os segmentos mais antigos do Exército, a exemplo dos Decretos-Lei $\mathrm{n}^{\circ} 353$ e 409de 1973, que fazia com que os quadros complementares ascendessem à oficialidade média mais rapidamente que os alunos da Academia Militar, ou seja, os militares carreiristas.

Motivados pelas questões corporativas acima mencionadas, que estavam na esteira da irredutibilidade do governo português quanto aos assuntos da guerra africana, os capitães de carreira começaram a se organizar em um movimento que se tornou cada vez mais politizado, dando origem ao Movimento das Forças Armadas (MFA).

A tendência crítica das Forças Armadas chegou estrondosamente ao domínio público quando o General Spínola lançou o livro Portugal e o Futuro em abril de 1974, cujos primeiros 50.000 exemplares, tal foi a curiosidade pública, foram vendidos em apenas 12 horas. (PEIXOTO, 2012) Este livro marcou a cisão entre a alta cúpula em matéria de guerra colonial, por oferecer uma nova abordagem à questão colonial, pois admitia que houvesse um nacionalismo tipicamente africano e, por

\footnotetext{
${ }^{18}$ A esse respeito ver o depoimento de Humberto Rodrigues, presidente da Associação Nacional dos Deficientes das Forças Armadas de Portugal (ADFA). (ONU, 1974-1995).
} 
consequência, a solução não poderia ser dada através de combate armado, mas em matéria de autodeterminação às nações africanas e o direito ao voto. (Peixoto, 2012) Com isso, Spínola não pretendia desmembrar a nação multirracial portuguesa, mas transformar o pluricontinentalismo para algo mais parecido com um plurinacionalismo.

A cisão no seio das Forças Armadas portuguesas em relação ao futuro da guerra colonial significava algo muito grave em um país em que a maioria das pastas ministeriais era ocupada por militares (Anderson, 1966), ainda mais em um contexto em que boa parte dos observadores internacionais não via uma saída para a guerra que não fosse por via da independência dos povos africanos. Apesar de Spínola não ter tido participação na formação do MFA, foi unido a este grupo que na alvorada do dia 25 de abril de 1974, os militares tomaram o poder, dando fim ao Estado Novo português, sob a Junta de Salvação Nacional (JSN), presidida pelo próprio Spínola. Com isso, dava-se novo fôlego e alento ao processo de independência angolano, embora seu final ainda estivesse incerto.

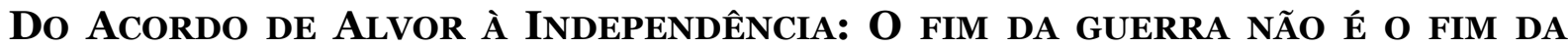 GUERRA}

A derrubada do governo de Marcelo Caetano e de Américo Thomaz, o então presidente, apesar de ter oferecido ao mundo a expectativa de um giro completo na tomada decisória quanto às guerras africanas, mostrou-se, na realidade, muito mais lenta com o passar dos dias. O problema colonial, que esteve no cerne do MFA, também foi o elemento que trouxe as maiores divergências no seio do governo recéminstalado.

A cúpula da JSN (constituída, em sua maior parte, por generais e oficiais de primeiro escalão do Exército, entre eles o próprio Spínola) e o MFA não entraram em um consenso fácil quanto às medidas mais imediatas da questão da guerra travada em Angola e, além disso, os pronunciamentos da JSN não tranquilizaram a opinião pública por conta das vagas assertivas acerca dos temas do ultramar. Neste ínterim, governantes do mundo todo, especialmente os da África, cobravam um posicionamento mais firme por parte do governo português e, em um discurso na assembleia da OTAN, Mário Soares, então Ministro dos Negócios Estrangeiros, disse que um cessar-fogo era a prioridade para a questão de Angola, embora não precisasse 
exatamente como a suspensão dos conflitos seria efetivada. (Peixoto, 2012) Esse mesmo ministro, em entrevista concedida logo após o 24 de abril, resumiu muito bem o momento incerto em que se encontrava o governo provisório do General Spínola àquela altura:

Quando aceitei a pasta dos Negócios Estrangeiros, tinha uma ideia para levar a bom termo a descolonização. Pretendia fazer assinar rapidamente um cessar-fogo nos territórios em guerra, para acabar com ela localmente. Mas tinha de respeitar o presidente Spínola, o qual possuía os seus próprios pontos de vista nessa matéria. Ele desejava a constituição de um processo sob controlo armado, para chegar a uma espécie de "Commonwealth portuguesa". Numa altura em que a opinião pública apelava à manifestação nas ruas a favor das independências, da fraternidade e da paz, isso era claramente impossível. A população reclamava o regresso dos seus soldados ao País. As tropas portuguesas estacionadas no Ultramar começavam, também elas, a confraternizar com os nacionalistas. A política de Spínola era, por conseguinte, irrealista. (POUCHIN, 2003, p. 55)

No dia nove de agosto de 1974, a JSN tornou pública a forma como se daria o processo da retirada de tropas portuguesas de Angola, que pode ser resumida em três pontos principais: o novo governo em Angola seria estabelecido a partir de uma coligação entre os três grupos nacionalistas principais levando em conta todas as etnias do país (inclusive a branca), uma Lei Eleitoral deveria ser estabelecida e, por fim, haveria a eleição de uma Assembleia Constituinte no prazo de dois anos, quando seria decidida a forma dos laços que Angola teria com Portugal.

Dois elementos saltam aos olhos nesta resolução: primeiro, ela foi feita sem a consulta ou o conhecimento prévio de nenhum dos grupos políticos em Angola. E depois, ela implicitamente sugere que os laços com Portugal poderiam ser mantidos (talvez ao gosto da commonwealth de Spínola) ou que, no melhor dos casos, a independência viria em - no mínimo - dois anos. (PEIXOTO, 2012)

Spínola parecia estar postergando para o futuro a resolução do mesmo problema que o colocara na chefia do país. O fracasso da sua política de uma independência "depressa, mas sem pressa", a insatisfação internacional que caminhava para colocá-lo na berlinda isolacionista onde uma vez estivera Salazar e, por fim, a insatisfação do MFA que não aceitou negociações quanto à rápida retirada de tropas de Angola foram fatores que culminaram na sua renúncia à presidência ao 
dia 30 de setembro de 1974. A partir deste ponto, a ala mais à esquerda do MFA esteve à frente das decisões políticas do país.

Uma vez que o MFA assumiu a pauta da solução dos conflitos em Angola e abriu novas linhas de diálogo com os representantes dos respectivos grupos nacionalistas, estes foram dispondo-se, unilateralmente, a aceitar o cessar-fogo. Embora representantes do MFA houvessem desembarcado em Angola logo em abril para tratar do armistício, o MPLA e a FNLA não aceitaram desarmar-se e dispersar suas tropas sem garantias prévias (e concretas) de independência.

O General Spínola e Mobutu, então presidente do Zaire ${ }^{19}$, haviam se encontrado no começo de setembro para discutir a trégua da FNLA, que só foi efetuada ao dia 15 de outubro de 1974. Este grupo foi o único que dialogou com Portugal através de um país estrangeiro porque, diferentemente do MPLA, não contava com representações em Lisboa ou Luanda e sua atuação estava centrada na região limítrofe entre Angola e Zaire. Apesar de não somar forças que cobrissem grandes porções territoriais, a FNLA representava uma forte ameaça militar por poder contar com o aparato logístico e bélico zairense e, através deste país, também contava com ajuda norteamericana.

A Revolução dos Cravos havia aberto novas possibilidades à organização política já que haviam sido afrouxadas as amarras às liberdades de opinião e associação e a PIDE não era mais um fator com o qual os angolanos teriam que se preocupar. Vários grupos políticos menores começam a surgir, embora sem apoio externo ou grande simpatia pública. A partir de agosto de 1974, a Frente de Libertação do Enclave de Cabinda (FLEC), grupo separatista da rica região produtora de petróleo e diamantes, tomou fôlego. Contudo, seus objetivos foram repudiados pelos três grupos angolanos, seguidos pela OUA e pela ONU. (PEIXOTO, 2012)

Além da FLEC, a questão racial a partir da Revolução dos Cravos mostrou-se não ser apanágio dos locais mais interioranos de Angola. Grupos brancos de Luanda, que comandavam a maior parte do aparato administrativo, de infraestrutura e de transporte do país e que, depois da África do Sul, representavam a maior população branca na África, começaram a flertar com a ideia de uma solução “à rodesiana"2o

\footnotetext{
${ }^{19}$ A República Democrática do Congo, ex-Congo Belga ou Congo Leopoldville, teve o nome mudado para Zaire entre 27 de outubro de 1971 e 17 de maio de 1997.

${ }^{20}$ A expressão faz alusão à tomada de poder por uma minoria branca sob a liderança de Ian Smith em 1965, que impôs um forte regime de segregação racial na Rodésia do Sul (Zimbabwe) (VISENTINI, op. cit.). Os colonos brancos organizaram a proclamação, unilateral, de independência antes que ela ocorresse sob a vontade da
} 
para Angola. A minoria branca, quando viu o MFA paulatinamente ganhar força em Portugal e, por fim, assistiu a renúncia de Spínola, começou a temer que a hegemonia política do país caísse nas mãos dos movimentos nacionalistas. Contudo, a única ação concreta derivada destes grupos, aglutinados principalmente em torno da FRA (Frente de Resistência em Angola) e do PCDA (Partido Cristão Democrático de Angola), foi a invasão, logo frustrada por forças nacionalistas de Angola, das vilas de Bailundo e da Cela. A partir daí, a ideia de uma solução à rodesiana para Angola perdeu integralmente a força. (PEIXOTO, 2012)

Dificilmente grupos surgidos após a Revolução dos Cravos conseguiram angariar a legitimidade necessária para competir em prestígio e reconhecimento com aqueles grupos que haviam participado durante os treze anos da luta anticolonialista. Em função disso, também não conseguiram fomentar o palanque adequado para se fazer representar e reconhecer perante a OUA, a ONU ou Portugal, além de serem boicotados pelos grupos pré-existentes. Sendo assim, de finais de outubro ao início de novembro, começaram os esforços de colaboração e diálogo entre representantes dos três movimentos angolanos e o governo de Portugal, que agora estava sob comando da ala mais esquerdista do movimento que depusera Caetano, o MFA. Entre três e cinco de janeiro de 1975 em Mombaça, no Quênia, ocorreu a primeira reunião de cúpula preparativa para uma segunda reunião, a acontecer dez dias depois, na cidade de Alvor no Algarve.

Dos princípios para a independência acordados nesta segunda reunião surgiu o Acordo de Alvor. Os pontos principais desse Acordo podem ser assim resumidos: (1) a independência de Angola ficaria agendada para o dia 11 de novembro de 1975 e até lá a administração do país estaria nas mãos de um governo provisório formado por um colegiado, com um representante de cada grupo, de presidência rotativa e cujas deliberações seriam tomadas por maioria simples; (2) o governo português estaria representado por um Alto Comissariado escolhido pelo presidente de Portugal, que não poderia intervir em assuntos governamentais, mas poderia ser consultado caso o governo provisório assim o desejasse; (3) não-discriminação étnica para os futuros critérios de nacionalidade; (4) uma Assembleia Constituinte seria formada no prazo de nove meses para a eleição do novo presidente a tomar posse em novembro; (5) uma Comissão de Defesa Nacional, formada pelo colégio presidencial, Alto

população negra; o governo de Ian Smith não foi reconhecido por Londres, capital de sua ex-metrópole, mas ganhou a simpatia da África do Sul. 
Comissariado e Estado Maior Unificado, seria formada com o principal propósito de unir os contingentes militares (então pulverizados entre os três grupos) e formar um Exército Nacional; (6) formação dos Ministérios com as chefias divididas entre os grupos. (PEIXOTO, 2012)

No dia 31 de janeiro de 1975, como havia sido previsto, foi lançado o novo governo de transição. Contudo, dois problemas de origem cercearam o bom funcionamento do Acordo de Alvor: o primeiro deles é que todas as partes haviam se comprometido a manterem-se nas posições ocupadas até então, o que não aconteceu porquanto os grupos lançaram-se rapidamente a reforçar seus contingentes; o segundo problema é que Portugal ficaria crescentemente incapaz de chefiar e resguardar de possíveis conflitos a Comissão Nacional de Defesa, uma vez que no seu próprio território a tênue coalizão de forças entre socialistas e comunistas na cúpula do MFA havia se encaminhado à beira de uma verdadeira guerra civil, situação que ficou pior após uma tentativa de golpe de Estado por parte do General Spínola em março.

O Acordo de Alvor, logo ficou claro, havia conseguido a perspectiva da independência concreta, mas não trouxera governabilidade ao seu governo de transição. Seus ministros não conseguiam atingir consensos e a Comissão de Defesa foi esvaziando-se com o respaldo de Portugal, de forma que entre 16 e 20 de junho houve uma tentativa de recomposição do que havia sido acordado em Alvor através de uma reunião em Nakuru no Quênia - uma espécie de Alvor II.

Esta tentativa mostrou-se insuficiente e, em julho de 1975, a não ser pelos ministérios encabeçados pelo MPLA, o governo de transição havia se tornado completamente inoperante. Logo a seguir começou uma verdadeira "corrida ao pódio" ao onze de novembro, em que o prêmio seria a chefia do novo governo de Angola. Para completar o quadro, no dia 22 de agosto, Portugal formalizou a suspensão parcial de Alvor: tudo se mantinha igual, mas Portugal lavava as mãos de salvaguardar a trajetória pacífica do governo de transição à independência em novembro. (PEIXOTO, 2012)

Conquanto Angola fosse um "pequeno e obscuro país africano," recém-colocado ante a perspectiva de independência, o ano de 1975 mostrou-se como um catalisador para transformar seu, até então, baixo perfil, na arena política internacional, em centro de divergências do confronto Leste-Oeste encetado pela Guerra Fria. A forma como os eventos se sucederam em Angola estava, em nível internacional, 
relacionadas a uma oleada de revoluções terceiro-mundistas iniciadas na década de 1970, que vieram na esteira da cisão sino-soviética em 1962, que fomentara um adensamento da participação soviética em conflitos periféricos como forma de reestabelecer seu papel na balança de poder mundial. (VISENTINI, 2004, p. 113)

A relação de que falamos não pode ser compreendia stricto sensu, pois cada país, seja Cambodja, Laos, Vietnã ou Angola, tinha seu próprio passado histórico e conjunturas sociais que renderam resultados diversos. O que os une em semelhança é a forma como contaram como peso determinado na balança internacional de poder, acalentando discussões acerca do conceito de détente ${ }^{21} \mathrm{e}$, para além dos conceitos, as implicações práticas que derivaram da interpretação feita pelo oponente. Assim, logo que o Acordo de Alvor foi assinado e os conflitos retomados em Angola, antever os resultados finais deste acordo, uma vez reconhecidas as simpatias internacionais que cabiam a cada um dos grupos, revestiu-se de grande importância simbólica aos Estados Unidos na esteira de sua perda catastrófica no Vietnã. ${ }^{22}$

Em 1975 os Estados Unidos eram governados por um presidente não-eleito, empossado após o vexame internacional do escândalo de Watergate - tornado epíteto da corrupção de alta cúpula. Caíra Richard Nixon (jan/1969 - ago/1974), mas sua "herança maldita" simbolizada pela catastrófica incursão no Vietnã, foi repassada à administração Gerald Ford (ago/74 - jan/1977), juntamente com o Secretário de Estado Henry Kissinger.

Diante da possibilidade da URSS aproveitar-se da fragilidade dos Estados Unidos em sua situação pós-Watergate e pós-Vietnã para empenhar-se em uma ação mais proativa em Angola, a Casa Branca efetivou mudanças na então estabelecida política de apoio tácito aos bastiões brancos formada pelo gabinete Nixon logo nos

\footnotetext{
${ }^{21}$ Segundo Magnoli, "o termo détente significa, literalmente, relaxamento. Na década de 1970 ganhou uso corrente no discurso das relações internacionais, exprimindo uma diminuição das tensões interestaduais, em particular um desanuviamento das relações entre as duas superpotências" (MAGNOLI, 1988. p. 9). Todavia, não nos propomos a lidar com a ideia de détente como um conceito ou um período histórico consolidado, com marcos temporais homogêneos e definidos. Segundo a definição de White, a détente é uma abstração retórica, que fora utilizada como elemento de discurso durante a Guerra Fria com finalidades políticas, de forma que a détente não se constituía em um "fim", mas em um "meio" (WHITE, 1981, pp. 165-171).

${ }^{22}$ Participando ativamente dos conflitos do Vietnã desde 1964, por apoiar o governo de Saigon (Vietnã do Sul) contra o Vietnã do Norte de Ho Chi Mihn, após o envio sistemático de tropas como também de apoio bélico, "em abril de 1975, as tropas do Vietnã do Norte e os guerrilheiros do Vietnã do Sul, entravam em Saigon, unificando o Vietnã e vencendo a mais longa, sangrenta e complexa guerra do Terceiro Mundo. Três potências haviam sido derrotadas - inclusive a mais poderosa nação no campo militar, econômico e tecnológico - por um pequeno país agrícola e periférico, ainda que com apoio diplomático e em armas dos países socialistas" (VISENTINI, op. cit, p. 115).
} 
seus primeiros meses de governo em 1969.23 Um segundo elemento, "menos global" desta mudança de postura, se devia às eleições de 1976: Ford, para conseguir apoio à sua candidatura pelos Republicanos deveria mostrar à população que o país ainda mantinha sua posição de prestígio e poderia, apesar do insucesso no Vietnã, mostrar força na arena internacional. (NOER, 1993, pp. 771-785)

O Acordo de Alvor, assinado em janeiro, deixou uma pequena margem de atuação ao planejamento de Gerald Ford: ou se deixava que os três grupos tratassem por si do governo do país, ou se escolhia dar apoio a um grupo de forma a propiciar o surgimento de um governo que lhe fosse favorável. A última opção foi acatada.

O primeiro sinal concreto dessa mudança de posição em relação a Angola foi a nomeação do diplomata Nathaniel Davis para a representação estadunidense no país. Davis ganhara notoriedade internacional por ter ocupado representação análoga no Chile quando dos esforços encobertos da CIA na derrubada de Salvador Allende dois anos antes; o resultado de sua nomeação não tardou a causar alarme na África: em 21 de fevereiro de 1975, em reunião ministerial da OUA, uma resolução votada por unanimidade, arguiu contra a nomeação do diplomata, de reconhecida participação na “ação dos Estados Unidos de desestabilização política na América Latina.” Apesar disso, a nomeação seria confirmada em 11 de março. (DAVIS, 1978, p. 110) Entre janeiro e fevereiro, U\$300.00o foram entregues à FNLA, através do Zaire, além de materiais bélicos. (NOER, 1993, pp. 771-785)

Com a ajuda econômica estadunidense e amplo apoio do bem treinado e equipado Exército zairense, em 25 de março a FNLA inaugurava sua marcha em direção a Luanda proclamando a cidade de Carmona 24 como sede oficial de sua incursão, liderada pela figura centralizadora de Holden Roberto. (Marquez, 1976) Poucas semanas depois, em cinco de agosto, tropas da África do Sul atravessaram a fronteira sul de Angola através do território da Namíbia sob pretexto de proteger o complexo de barragens de Ruacana-Calueque dos meandros da guerra. Nesta região

\footnotetext{
${ }^{23}$ O planejamento de Nixon para os bastiões brancos da África Austral - a dizer, as colônias portuguesas, Rodésia do Sul (Zimbabwe) e África do Sul - fora consolidado através do Memorando de Estudos 39 do Conselho Nacional de Segurança (NCSM 39) que, em uma palavra, afirmava que a minoria branca "estava lá para ficar", de forma que o Gabinete Nixon optou pela seguinte posição: manter, ante a opinião pública, oposição às repressões radicais, mas relaxar a política de isolacionismo e restrições econômicas aos grupos brancos no poder. Desde então a FNLA deixou de receber apoio militar dos EUA (NOER, 1993, pp. 771-785).

${ }^{24}$ Atual cidade de Uíge, localizada no centro-sul do distrito homônimo (é também a sua capital).
} 
estavam estacionados contingentes da UNITA, mostrando que a parceria entre esse grupo e Pretória estaria selada (MARQUEZ, 1976)25.

Ao final do mês de julho, após discussões internas quanto à opção por passar por cima do Congresso e disponibilizar mais fundos para ações em Angola, por decisão da Casa Branca, 14 milhões de dólares foram aprovados para apoio à FNLA e à UNITA - quantia que aumentou à cifra de 25 milhões um mês depois, e a 32 milhões em setembro (NOER, 1993). As discussões derivavam do risco de não conseguir os efeitos desejados em Angola e ainda agir contra o Congresso e acabar sendo relacionado à África do Sul - o que não agradou a uma população com seus próprios problemas raciais não-resolvidos; o próprio Davis se mostrou contrário ao impulso da Casa Branca, preferindo os "bons ofícios" como saída à situação. O diplomata calculava que não haveria jeito de participar massivamente, enviando homens, sem que o Congresso soubesse, e se não fosse assim, os riscos não valeriam a pena pelas divergências de opinião. Davis pediu exoneração do cargo. (DAVIS, 1978, pp. 109-124).

A situação do MPLA, apesar de ser o movimento com maior cobertura da ação de guerrilha, neste meio-termo, era bastante preocupante: a FNLA pressionava-o ao norte, enquanto que ao sul e sudoeste, a UNITA aliava-se sistematicamente à África do Sul. O mês de agosto, contudo, inaugurou um fato novo aos desdobramentos da guerra: foi o momento em que Agostinho Neto pediu auxílio a Cuba, por meio de delegação cubana que aportava em Luanda. De forma que em setembro, os primeiros contingentes cubanos de apoio começaram a chegar: cerca de 500 técnicos e especialistas cubanos (o MPLA tinha armas recebidas previamente da URSS, mas, de forma geral, não sabia como utilizá-las), 25 morteiros e unidades móveis de artilharia antiaérea, um time de médicos, 115 veículos e complementos para formar uma estrutura de comunicação básica - esse contingente viajou em três navios improvisados e sobrecarregados: El Vietnam Heroico, El Coral Island e La Plata. (MARQUEZ, 1976). A presença cubana em Angola ficou manifesta a partir de então. ${ }^{26}$ O primeiro navio chegou no dia 4 de outubro a Pointe-Noire (a segunda maior cidade do Congo Brazzaville depois da capital); os outros dois chegaram,

\footnotetext{
${ }^{25}$ Localizado na fronteira sul de Angola, o complexo fora construído em parceria entre Portugal e África do Sul e suas barragens eram responsáveis pela distribuição de água para largas extensões do sudoeste africano.

${ }^{26}$ No dia 23 de setembro, Henry Kissinger disse em assembleia da ONU que a participação cubana na guerra de Angola tornara a situação do país muito delicada, mas negou qualquer participação direta dos Estados Unidos na questão (NOER, op. cit).
} 
respectivamente, nos dias sete e onze de outubro a Porto Amboim (cidade do distrito angolano de Cuanza Sul, próxima à cidade de Benguela). A esta altura as tropas de Holden Roberto estavam muito próximas a Luanda. (MARQUEZ, 1976).

O final de novembro marcou o início do rompante sul-africano sobre território angolano, pareando forças com a UNITA e a FNLA; suas colunas marchavam cerca de 70 quilômetros por dia, chegando, no dia três de novembro, à cidade de Benguela, sede de distrito homônimo (MARQUEZ, 1976); nesse mesmo dia, devido à ascensão dos conflitos, o Consulado Geral Americano foi fechado e seus cidadãos evacuados. (DAVIS, 1978, pp. 109-124). Frente aos avanços da FNLA e da UNITA em direção a Luanda, onde ocorreu a transição política como acordado por Alvor, para acontecer ao dia 11 de novembro, as lideranças do MPLA e de Cuba tiveram que fazer novas deliberações.

Em cinco de novembro, isto é, apenas seis dias antes de Portugal retirar-se completamente de Angola, Havana optou por agir mais incisivamente na questão. (Marquez, 1976). Dava-se início à Operação Carlota. ${ }^{27}$ A partir de então, tropas cubanas foram levadas, por via aérea, em um fluxo constante que somou no período de trinta dias um contingente de 650 homens. (MARQUEZ, 1976). Foram suficientes para bloquear o acesso da FNLA e da UNITA à capital, garantindo ao MPLA o controle da cidade de Luanda na noite de onze de novembro, quando a bandeira portuguesa no Palácio Nacional deu lugar à rubro-negra, com foice e martelo estilizados pelo MPLA.

Vinte e três países africanos, em reunião da OUA, reconheceram o recéminstalado governo do MPLA em 26 de novembro (nenhum, no entanto, reconheceu a FNLA ou a UNITA, que, unilateralmente, haviam igualmente declarado a independência de Angola). (NOER, 1993, pp. 771-785). A essa altura, a participação estadunidense no palco de operações angolano não teria mais como manter-se na sombra, de forma que ao dia 19 de novembro o Senado aprovou a Emenda Clark que cortava imediatamente todos os fundos para ações secretas em Angola (NOER, 1993).

Era uma vitória diplomática do MPLA, mas, como nos lembra Marcelo Bittencourt (2002), o fim da guerra não é o fim da guerra. A guerra civil sobreviveu à própria Guerra Fria. Seus desdobramentos, infelizmente, continuam a afetar a Angola dos dias de hoje.

\footnotetext{
${ }^{27}$ Nome dado em homenagem a outro cinco de novembro: em 1843, a escrava negra Carlota iniciava uma rebelião de escravos contra os espanhóis na região açucareira de Matanza, em Cuba.
} 


\section{REFERÊNCIAS BIBLIOGRÁFICAS}

\section{ACERVOS ON-LINE DE ORGANIZAÇÕES OFICIAIS}

ASSEMBLEIA DA REPÚBLICA PORTUGUESA - Direção de Serviços de Documentação e Informação. Acervo on-line de Debates Parlamentares. Disponível em: http://www.debates.parlamento.pt?pid=r2

ONU. Territórios sob a administração portuguesa (1974-1995). Documentos da Assembleia Geral e Conselho de Segurança. Disponível em http://www. guerracolonial.org/specific/guerra_colonial/documents_onu/un.sfw. Acesso: 20, set. 2013 .

OBRAS DE REFERÊNCIA

ANDERSON, Perry. Portugal e o fim do ultracolonialismo. Rio de Janeiro: Civilização Brasileira, 1966.

APPIAH, K.A. O mito de um mundo africano. In: Na casa de meu pai. Trad. V. Ribeiro. São Paulo: Contraponto, 1997, p.111-25.

ASANTE, S. K. B; Chanaiwa. O pan-africanismo e a integração regional. In. UNESCO. História geral da África. Vol. VIII: África desde 1935. Brasília: UNESCO, 2010.

BENDER, Gerald J. Angola, mito y realidades de su colonización. Cidade do México: Siglo Veintiuno, 1980.

Angola, the Cubans, and American anxieties. Foreign Policy, Washington, No. 31 (Summer, 1978), pp. 3-30.

BITTENCOURT, Marcelo. "Estamos juntos": o MPLA e a luta anticolonial (19611974). 2 volumes. Tese (doutorado). Niterói: Programa de Pós-Graduação em História. Universidade Federal Fluminense, 2002. 
, A criação do MPLA. Estudos afro-asiáticos, 32: p. 185-206. Rio de janeiro, CEAA/UCAM, dezembro de 1997a.

, A criação do MPLA. In: Dos jornais às armas. Veja: Lisboa, 1999.

, A história contemporânea de Angola. Construindo o passado angolano: as fontes e a sua interpretação. Actas do II Seminário Internacional sobre a História de Angola (4-9 de agosto de 1997b). Luanda, Comissão Nacional para as comemorações dos Descobrimentos Portugueses, 2000, pp. 161-185.

, Memórias da guerrilha: a disputa de um valioso capital. História Oral.

Revista da Associação Brasileira de História Oral, No. 2, junho de 1999. Rio de Janeiro, pp. 91-110.

, Modernidade e atraso na luta de libertação angolana. In REIS, Daniel Aarão e ROLLAND, Denis (Orgs.) Modernidades alternativas. Rio de Janeiro: Ed. FGV, 2008. pp. 277-294.

CERVO, Amado; Bueno, Clodoaldo. História da política exterior do Brasil. Brasília: EdUNB, 2010.

CHALIAND, Gerard. Mitos revolucionários do Terceiro Mundo. Rio de Janeiro: Francisco Alves, 1977.

CROWDER, Michael. A África sob domínio britânico e belga. In. UNESCO. História geral da África. Vol. VIII: África desde 1935. Brasília: UNESCO, 2010.

DAVIDSON, Basil. Congress organizations and revolutionary movements: The real differences. Review of African Political Economy, Taylor \& Group, No. 5 (Jan. - Apr., 1976), pp. 99-102.

, On revolutionary nationalism: The legacy of Cabral. Latin American Perspectives, Vol. 11, No. 2 (Spring, 1984), pp. 15-42.

, Questions about Nastionalism. African Affairs, Oxford University Press, Vol. 76, No. 302 (Jan. 1977), pp. 39-46. 
. South Africa and Portugal. A journal of opinion, African Studies Association, Vol. 4, No. 2 (Summer, 1974), pp. 9-20.

Angola in the tenth year: a report and analyses, may-july 1970. Africa Affairs, Oxford University Press, Vol. 70, No 278 (Jan, 1971), pp. 37-49.

DAVIS, Nathaniel. The Angola decision of 1975: A personal memoir. Foreign Affairs, Vol.57, No. 1 (Fall, 1978), pp. 109-124.

DIOP, Mahjemout. A África tropical e a África equatorial sob o domínio francês, espanhol e português. In. UNESCO. História geral da África. Vol. VIII: África desde 1935. Brasília: UNESCO, 2010.

FANON, Frantz. Os condenados da Terra. Juiz de Fora - MG, Editora UFJF, 2006.

FERRO. Marc. História das colonizações. São Paulo: Companhia das Letras, 1996.

HOBSBAWM. Eric J. A era dos extremos. O breve século XX (1914-1991). São Paulo: Companhia das Letras, 1995.

MAGNOLI, Demetrio. Da Guerra Fria à Détente. Campinas: Papirus, 1988.

MARQUEZ, Gabriel Garcia. Operation Carlota. New Left Review I/101-112, January-April $1976 . \quad$ Disponível em: http://www.newleftreview.org/?page=article\&view. Acesso em 15.09.2013.

NOER, Thomas J. International credibility and political survival: The Ford Administration's intervention in Angola. Presidential Studies Quaterly, Center for the Study of the presidency and Congress, Vol. 23, No. 4, (Fall, 1993), pp. 771785 .

PEIXOTO, Carolina Barros Tavares. Limites do ultramar português, possibilidades para Angola: o debate político em torno do problema colonial (1951-1975). (dissertação de mestrado) - Universidade Federal Fluminense, Niterói, 2009. 
PÉLISSIER, René. História das campanhas de Angola. Resistência e revolta. Lisboa: Estampa, 1997

PINHEIRO, Letícia. Foreign policy decision-making under the Geisel government: The president, the military and the foreign policy. (Tese Doutorado) - London School of Economics and Political Science, Londres, 1994.

PINTO, João Alberto da Costa. Gilberto Freyre e a intelligentsia salazarista em defesa do Império Colonial Português (1951-1974). História, São Paulo, 28 (1): 2009, pp. 445-482.

POUCHIN, Dominique (Org.). Mario Soares. Memória viva. Vila Nova de Famalicão: Quase Edições, 2003.

ROAPE, Publications. The Struggle in Angola. Review of African Political Economy, No. 5 (Jan. - Apr., 1976), pp. 80-94.

RODRIGUES, Luiz Nuno. “Orgulhosamente sós”? Portugal e os Estados Unidos no início da década de 1960. Comunicação apresentada ao $22^{\circ}$ encontro de Professores de História da Zona Centro. Caldas da Rainha. IPRI: 2004. Disponível em: http://ipri.pt /investigadores/artigo.php? Acessos em 15.09/2013.

SILVA, Márcia Maro da. A independência de Angola. (Tese Doutorado) Instituto Rio Branco, Brasília, 2008.

UNESCO. História geral da África. Vol. VIII: África desde 1935. Brasília: UNESCO, 2010.

VISENTINI, Paulo, A Guerra Fria. O desafio socialista à ordem americana. Porto Alegre: Leitura XXI, 2004.

A África moderna: um continente em mudança (1960-2010). Porto Alegre: Leitura XXI, 2010.

VISENTINI, Paulo; RIBEIRO, Luiz Dario; PEREIRA, Analúcia. Breve história da África. Porto Alegre: Leitura XXI, 2007. 
WALLESTEIN, Immanuel. Franz Fanon: Reason and violence. Berkeley Journal of Sociology, California, Vol. 15 (1970), pp. 222-231.

WHITE, Brian. The concept of détente. Review of International Studies, Cambridge, Vol. 7, No. 3 (Jul. 1981), pp. 165-171.

Zoraide Portela Silva: Doutora em Letras (Estudos Comparados de Literaturas de Língua Portuguesa) pela Universidade de São Paulo. Mestre Estudos Literários pela Universidade Federal de Minas Gerais. Possui graduação em Habilitação em Português e Literatura da Língua Portuguesa pela Universidade Estadual do Sudoeste da Bahia. Atualmente é professora Assistente no Departamento de Ciências Humanas da Universidade do Estado da Bahia.

Artigo recebido para publicação em: julho de 2016

Artigo aprovado para publicação em: setembro de 2016

\section{Como citar:}

SILVA, Zoraide Portela. Guerra Colonial e Independência de Angola: O fim da guerra não é o fim da guerra. Revista Transversos. "Dossiê: História Pública: Escritas Contemporâneas de História". Rio de Janeiro, Vol. 07, nº. 07, pp. 154184, Ano 03. set. 2016. Disponível em: <http://www.epublicacoes.uerj.br/index.php/transversos $>$ ISSN 2179-7528. DOI: 10.12957/transversos.2016.25600.

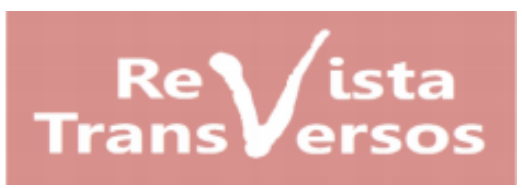

